\title{
Inflation Targeting Monetary Policy and Unemployment in South Africa
}

\author{
Harris Maduku, Irrshad Kaseeram \\ University of Zululand, Department of Economics, KwaDlangezwa Campus, South Africa \\ madhukuharris@gmail.com, KaseeramI@unizulu.ac.za
}

\begin{abstract}
We analyze the impact of inflation, growth and exchange rate on unemployment in South Africa using annual data spanning 1980-2017. Using the ARDL methodology we find that there is a negative longrun relationship between inflation and unemployment in South Africa and inflation is significant in explaining unemployment. Other variables of interest, economic growth and exchange rate are also significant in explaining unemployment. We use the findings of our study to propose that the South African Reserve Bank(SARB) should consider revising its objectives so that they can consider getting involved in targeting unemployment so that they help nurse the economy from the wounds of high inequality and poverty.
\end{abstract}

Keywords: Monetary policy, Inflation targeting, unemployment,

\section{Introduction}

South Africa has been characterized by high levels of unemployment, poverty and inequality 23 years into its democracy. A lot of policies have been put in place by the government but these indicators have not responded as expected. Economic policies that are put in place by the government impact on unemployment and other mentioned indicators mainly through fiscal and monetary policy. This paper shall explicitly look at the impact of South Africa's monetary policy stance on unemployment. South Africa adopted a new monetary policy in 2000 which has only one objective, to target inflation so as to make sure that there is price stability in the country. This happens after the Reserve Bank of South Africa has been unofficially targeting inflation for 2 years before its official inception in 2000 (Mboweni, (2003); SARB, 2004). The disciples of inflation targeting (IT) monetary policy lean on the justification that ensuring price stability through targeting inflation will help to anchor inflation expectations. When economic agents are not expecting inflation to increase, that might facilitate saving and investment in the economy. Still on the idea of inflation expectations, the monetary policy trusts that lower inflation boosts investment in the economy hence create jobs and average incomes of citizens (Kabundi and Schaling, 2013). Also the supporters of IT justify themselves by arguing that targeting inflation and achieving a low inflation environment requires central bank independence and therefore improve policy credibility in the country. Basically assumptions behind inflation targeting monetary policy are meant to create a financially stable, investor and business-friendly environment (SARB, 2004). The central bank in order to achieve its main objective of stabilizing prices in the country is basically controlled by one main instrument which is the interest rate (SARB, 2004).

The interest rate will be used by the central bank to achieve both contractionary and expansionary monetary policy. The Bank will decrease the interest rate if they intend to expand the economy (making credit cheaper for consumption and investment) and this will grow the economy through boosting demand which will later lead to the growth of investments in the country and as a result help to reduce unemployment and poverty. The opposite will happen when the interest rate is increased by the Bank. However, given the situation in South Africa a lower interest rate will always be favorable to deal with low domestic investment and unemployment which is standing at 27,6\% (Stats SA, 2017). Although the Reserve Bank of South Africa has adopted inflation targeting monetary policy and made price stability its sole objective, statistics of a wide range of indicators in the country communicate that IT is not an appropriate policy for the country. The country is ranked as one of the most unequal countries in the world with a GINI coefficient of $66 \%$ as of 2016 (World Bank, WDI, 2017). Unemployment has continuously been increasing from 24.7 in 2012, 25.2 in 2015 and 26.7 in 2016.Poverty rates are estimated to be more than $50 \%$ as per recent statistics released by Statistics South Africa in 2017. The hardest hit by this kind of a policy is the youth who are the future of the country and the youth unemployment is standing at shocking statistics of $51.91 \%$. Economic growth grew by unpleasant figures however, failing to deal with problems of poverty and unemployment in the country. Real GDP grew by $2.489 \%$ in 2013 , by $1,298 \%$ in 2015 and by a paltry of $0.279 \%$ in 2016 (SARB, 2016). These are indications that there are problems with policies in the country specifically the monetary policy. However, those who believe in targeting inflation and achieve price stability as a priority argue that monetary policy 
influences inflation and the economy for example, the demand of goods and services and this leads to affecting the demand for labor who produce these goods and services. This relationship is actually assumed to occur through the influence of the financial conditions of households and firms (Ngalawa, 2009). This then means that monetary policy will be operating through various channels that include the exchange rate, interest rate channel and credit channel. Another assumption of inflation targeting (IT) rests on the argument that, since the interest rate is the main instrument, increasing it will help to tame monetary and credit expansion. The capital inflows that a high-interest rate attracts are then expected to offset all the economic consequences attached to a high-interest rate. This again exposes the fact that IT monetary policy relies much on external factors to solve domestic problems (Epstein, 2007). It explicitly favors low inflation to create a conducive environment for foreign direct investment (FDI) although there is weak empirical evidence that link low inflation and foreign direct investment (see Epstein, 2007).

The available Interesting empirical evidence is that FDI does not cause economic growth but economic growth causes FDI and this justifies why South Africa is supposed to be inward-looking in its policies of trying to achieve low inequality, low poverty rates and low unemployment. Epstein (2007) also had interesting findings of countries that adopted inflation targeting monetary policy as he argued that inflation is not one of the main determinants of foreign direct investment but low-interest rates play a critical role as well as less unequal economies. On the issue of interest rates, comparing South Africa with other emerging economy countries that it is usually compared with (Brazil, Russian, India and China), it has the highest unemployment figures and one of the highest interest rates. The table below shows the statistics:

Table 1: Comparison of Interest, Inflation and Unemployment Rate

\begin{tabular}{llll}
\hline & Interest rate & Inflation & Unemployment \\
\hline South Africa & $6.5 \%$ & $6.32 \%$ & $26.7 \%$ \\
China & $4.35 \%$ & $2.9 \%$ & $3.9 \%$ \\
India & $6 \%$ & $4.4 \%$ & $3.5 \%$ \\
Russia & 7.25 & $2.2 \%$ & $5 \%$ \\
Brazil & 6.5 & $2.9 \%$ & $12.5 \%$ \\
\hline
\end{tabular}

Source: World Bank (2017)

The statistics shown on the table above is explicitly evidenced enough to argue that the IT policy recommended to countries by the Washington consensus is not working well for South Africa. This kind of monetary policy has succeeded in most cases where it was implemented as far as anchoring inflation expectations and lowering inflation but it has not succeeded in creating an environment that creates jobs, reduces poverty and inequality. The IT policy has worked in South Africa but the Reserve Bank has struggled with hitting the target since inflation is always on the top band of the target and sometimes it goes outside the band. The most contributing factor to this difficultness is the exchange rate channel which affects inflation directly since South Africa is a small open economy involved in the importation of huge volumes of intermediate goods (Epstein, 2006). Imports are contributing much to headline inflation because the rand has been depreciating its value making the imports to be much expensive and with businesses passing on these exchange rate changes to prices, these are inflationary pressures that are giving the Bank serious problems.

\section{Literature Review}

This section will focus on a number of researches that were done in other countries where the same monetary policy was adopted. Only researches that are related to inflation and unemployment will be analyzed so that the relationship that exists between monetary policy and unemployment can be unveiled. We start by looking at the research on South Africa by Epstein (2002). Although this study was done in the early years of the monetary policy inception, its findings have come to be true. This study used literature to analyze if inflation targeting was the best monetary policy South Africa could adopt. In conclusion, the paper dismissed the benefits inflation targeting could bring to the South African economy since it argued that South Africa is a small economy hence opening it and allowing the value of the rand to be controlled by the market 
forces is going to make it vulnerable. Epstein (2002) recommended that South Africa should tighten its exchange rate rather than leaving it loose. Also he recommended that South African policymakers should insulate the country's financial market from the international capital markets through implementing policies like lending windows, underwriting facilities, asset-based reserve requirements and subsidized credit. This in short meant that the authorities should think of a policy shift that would move away from just focusing on price stability and opening the economy.

Blinder (2000) and Parsley (2012) concur with the findings and recommendations by Epstein (2002) and they argue that there are better approaches that countries with high unemployment and poverty should adopt when the inflation targeting monetary policy has failed to achieve what the advocates thought it would. Recommendations that come from this work point to the fact those countries that have adopted inflation targeting (IT) but it has failed to deal with poverty and unemployment should quickly abolish it and start reducing the interest rate to promote growth and later on achieve reduced unemployment and poverty. One of the early studies to investigate the role of monetary policy on unemployment was Leeper, Sims and Zha (1996). The study uses a VAR model with monthly data spanning 1960 to 1996 and the findings suggest that a monetary policy that is contractionary in nature does negatively affect employment. The study recommends that if an economy is troubled with high levels of unemployment and poverty, should look at benefits that can be achieved from adopting an expansionary monetary policy with instruments like the interest rate playing a kingship role in stimulating employment. In line with the findings of Leeper, Sims and Zha, an American study by Christiano, Eichenbaum and Evans (1999) also uses a VAR approach and find that contractionary monetary policy shocks cause a fall in employment.

Analyzing the relationship between monetary policy and unemployment in Sweden, Alexius and Holmlund used a structural vector autoregressive (SVAR) methodology. Alexius and Holmlund (2007) use quarterly data spanning 1980 to 2005 on the output gap, unemployment, monetary conditions index, foreign output gap, technology and government deficit. The study finds out and concludes that expansionary monetary policy increases the output gap and as a result reduce the level of unemployment in a country. Walsh (2009) in an effort to find the relationship between inflation targeting and economic growth used a propensity score matching estimation technique and examined seven inflation targeting and other fifteen that were not targeting inflation but they are all industrialized economies. The study finds that IT has no significant impact of output growth. On a similar note, a study by Daboussi (2014) employed a panel data analysis of inflation targeting and non-targeting countries using an extended form of difference-in-difference estimation methodology. The findings of the study indicate that inflation targeting significantly lowers inflation volatility and enhances economic performance. The argument to this rest on the fact that IT reforms the behavior of monetary authorities in a way and manner they operate their instruments. To the interest of this study, the work of Daboussi (2014) failed to account for the effects of the economic development of economic performance and also the issue of financial development and this makes the benefits a country can realize from adopting IT in this case very inconclusive.

\section{Methodology}

This section will focus on the tools and methods used to gather and analyze data for this research. The main goal of this research is to investigate the impact of the South African monetary policy on unemployment. To determine the impact of monetary policy on unemployment, most studies opted for the Vector Autoregressive method but the current study employed the bounds testing AutoRegressive Distributed Lag (ARDL) approach for cointegrated series. Annual data spanning from 1980 to 2017 for the Unemployment rate (unemp), inflation rate (inf), economic growth rate (growth), real effective exchange rate (reer) and broad money is used in this study. Data used for this study was downloaded from the South African Reserve Bank (SARB) website, World development indicators (World Bank) and the International Monetary fund database. Graphs below explicitly show the behavior of each and every variable in their level form for the period covered by this study. Inflation shows a downward trend although with a big upward shock during the period of the 2007-2008world financial crisis. Unemployment shows an upward trend just before the inception of the inflation targeting monetary policy in 2000 although showing a decreasing trend a few years after IT before it starts to increase again. Economic growth has no consistent trend it is following but it shows that the rate it has been growing since the new monetary policy is less than before the new policy was put in place. The real 
effective exchange rate does show continuous depreciation especially after the introduction of the monetary policy and the interest rate fluctuates between 5 and $7 \%$ for the rest of the period after the new monetary policy.
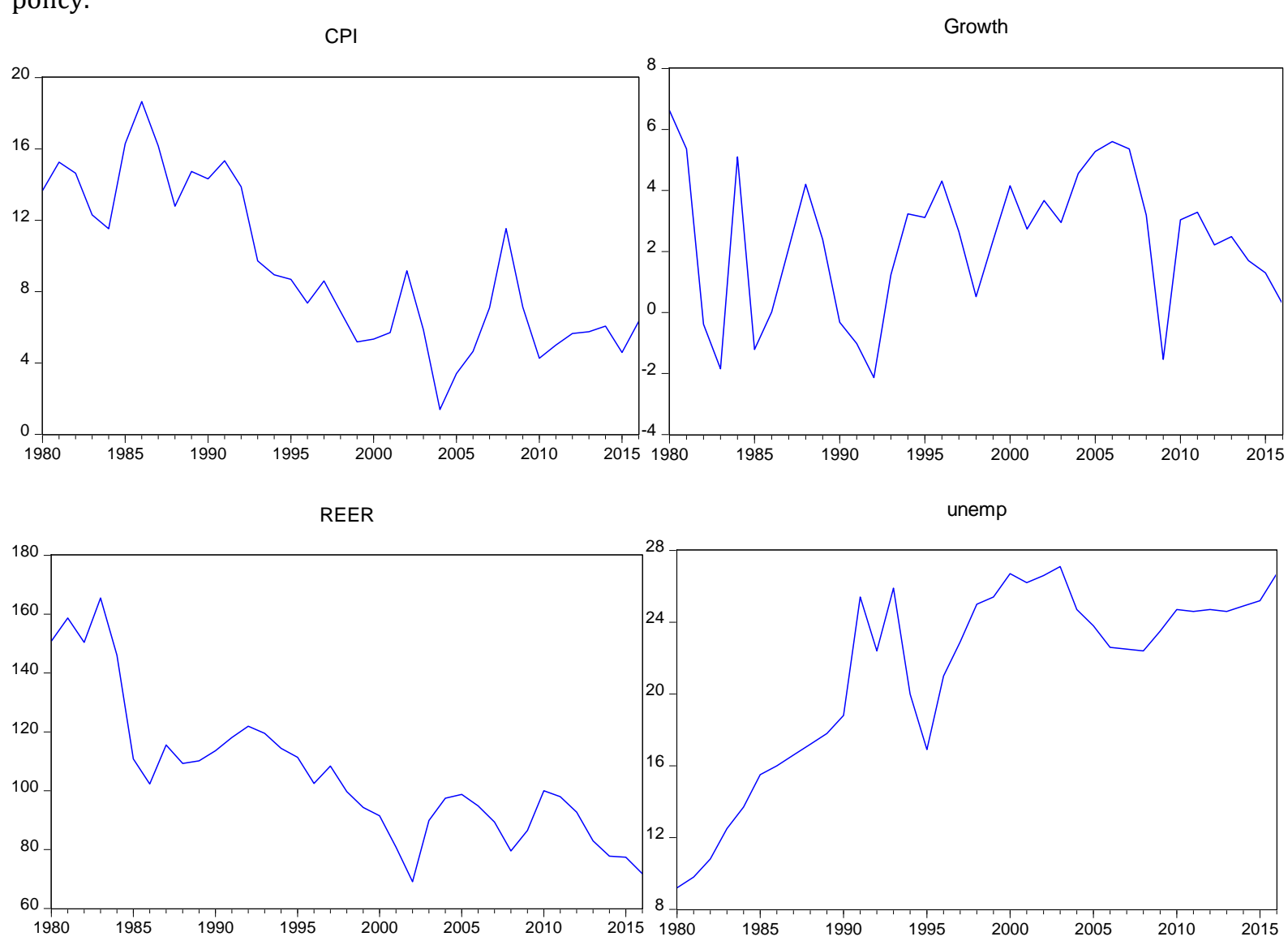

Graph 1: Source; Author's own calculation.

As mentioned above, this work uses the ARDL as the main methodology for estimating the unemployment equation. The model is adapted from the work of Pesaran, Shin and Smith (1996) and the modified version of the previous work by Pesaran and Shin (1999). We decided to use this methodology because (1) no work to the best of our knowledge has used it to investigate this kind of relationship in the case of South Africa (2) it allows the researcher to model variables that are of different orders of integration meaning that it can mix those variables stationary in their levels I(0) and those stationary after first differencing I(1). The basic ARDL model for cointegration testing that this paper will use is shown below in equation 1.

$\Delta X_{t}=\delta_{0 i}+\sum_{i=1}^{k} \alpha_{i} \Delta X_{t-1}+\sum_{i=1}^{k} \alpha_{2} \Delta Y_{t-i}+\delta_{1} X_{t-1}+\delta_{2} Y_{t-1}+V_{i t}$

$\mathrm{k}$ is the ARDL model maximum lag order and chosen by the user. The F-statistic is carried out on the joint null hypothesis that the coefficients of the lagged variables $(\delta 1 \mathrm{X} t-1 \delta 1 \mathrm{Yt}-1$ or $\delta 1 \mathrm{Y} t-1 \delta 1 \mathrm{Xt} t-1)$ are zero. $(\delta 1-\delta 2)$ correspond to the long-run relationship, while $(\alpha 1-\alpha 2)$ represent the short-run dynamics of the model.

The hypothesis that the coefficients of the lag level variables are zero is to be tested.

The null of the non-existence of the long-run relationship is defined by;

Ho: $\boldsymbol{\delta} \mathbf{1}=\boldsymbol{\delta} \mathbf{2}=\mathbf{0}$ (null, i.e. the long run relationship does not exist)

H1: $\boldsymbol{\delta} \mathbf{1} \neq \boldsymbol{\delta} \mathbf{2} \neq \mathbf{0}$ (Alternative, i.e. the long run relationship exists)

The first step that we take when dealing with the time series data that we have is to check its stationarity. Using the Augmented Dickey Fuller (ADF) we find that all the variables are nonstationary in their levels and they only get stationary after first difference I(1). We did the second unit root tests to confirm the results of the ADF using the Phillips Perron (PP). Also the PP confirms that we do not have a variable that is stationary in its levels but they all become stationary after they have been differenced once I(1). Before running the 
employment equation using the ARDL, it is a basic requirement that one has to start by conducting the bounds test to observe if the dependent variable is cointegrated with its regressors or explanatory variables. However, we cannot run this test if our dependent variable is stationary in its levels (Pesaran and Shin, 1996). It is not a problem if the explanatory variable is I(0) as long as the dependent variable is I(1). In addition, we cannot run a bounds test if we have any of our variables getting stationary after second difference I(2) since the assumption of the bounds testing assumes that the variables are either I(0) or I(1). The long-run relationship between variables is observed after we have computed the W-statistic and Fstatistic for testing the significance of the lagged variables in their level form in the error correction form of the underlying ARDL model. We are using yearly data spanning from 1980 to 2017 so we allowed the system to choose the number of the lags and it chose 4 lags.

Table 2: Unit root test results, 2005

\begin{tabular}{|c|c|c|c|c|c|}
\hline & Levels & & $\begin{array}{l}\text { First } \\
\text { difference }\end{array}$ & & \\
\hline Variable and test & Constant & $\begin{array}{l}\text { Constant and } \\
\text { trend }\end{array}$ & Constant & $\begin{array}{l}\text { Constant and } \\
\text { trend }\end{array}$ & $\begin{array}{c}\text { Level of } \\
\text { stationarity }\end{array}$ \\
\hline \multicolumn{6}{|l|}{ ADF test } \\
\hline Unemp & -2.203 & -2.406 & -6.592 & -6.704 & $\mathrm{I}(1)$ \\
\hline Inf & -1.487 & -1.101 & -2.732 & -4.976 & $\mathrm{I}(1)$ \\
\hline Lreer & -1.452 & -3.633 & -5.169 & -5.101 & $\mathrm{I}(1)$ \\
\hline Growth & -4.309 & -4.395 & -7.042 & -6.939 & $\mathrm{I}(1)$ \\
\hline Interest & -5.477 & -5.141 & -8.654 & -8.457 & $\mathrm{I}(1)$ \\
\hline \multicolumn{6}{|l|}{ Phillips Peron } \\
\hline Unemp & -2.387 & -2.356 & -6.698 & -7.643 & $\mathrm{I}(1)$ \\
\hline Inf & -1.455 & -2.805 & -7.999 & -9.111 & $\mathrm{I}(1)$ \\
\hline Lneer & -1.133 & -2.476 & -5.818 & -6.052 & $\mathrm{I}(1)$ \\
\hline Growth & -4.321 & -4.393 & -8.906 & -8.619 & $\mathrm{I}(1)$ \\
\hline Interest & -5.297 & -5.051 & -11.887 & -12.218 & $\mathrm{I}(1)$ \\
\hline
\end{tabular}

Source: Author

The table below shows the results of the bounds testing results and using the F-statistic, we conclude that there exists a long-run relationship amongst the dependent variable and the explanatory variables. We made such a conclusion because we know that according to Pesaran and Shin (1996), as long as the F-statistic lies outside the upper bound then there is a long-run relationship. When the F-statistic is outside the upper bound, the null hypothesis that there is no relationship is rejected. Therefore, inflation, growth, Ireer and interest can be said that they are the long-run facilitating variables and they can help to explain unemployment.

Table 3: Bounds Test Results

\begin{tabular}{lrcc}
\hline t-Bounds Test & & \multicolumn{2}{c}{ Null Hypothesis is: No levels relationship } \\
\hline Test Statistic & Signif. & $\mathrm{I}(0)$ & $\mathrm{I}(1)$ \\
10.661 (F-statistic) & $10 \%$ & 3.03 & 4.06 \\
& $5 \%$ & 3.47 & 4.57 \\
-6.145 (W-statistic) & $10 \%$ & -2.57 & -3.86 \\
& $5 \%$ & -2.86 & -4.19 \\
\hline
\end{tabular}

Source: Author's own calculation

After the bounds test we identify that there exists a long-run relationship between the dependent variable and the independent variable and this allows us to continue to run our ARDL model. The ARDL is lag sensitive and each variable will have the appropriate number of lags. Using the AIC the system chose the appropriate number of lags for each variable and only the significant ones will be available as the insignificant ones will automatically be removed from the system. When we ran our unemployment model, the ARDL system chose $(1,4,3,2,2)$ and this means that 1 lag for the dependent variable (Unemp), 4 lags for inflation (Inf). 3 lags for logged real effective exchange rate (Lreer), 2 lags for economic growth rate (growth) and 2 lags for the 
monetary policy dummy variable (IT dummy). We will have a look at the diagnostic tests of this model to see if our model is stable using the Cusum test.

Model Stability test (Cusum test): The instruments we used to do the diagnostic checks for our $(1,4,3,4,2$, 2) model indicates that there is no serial correlation and also the model is stable since there is nothing that is outside the borders of the cusum test. After knowing that our model satisfied the pre-estimation conditions, we then took the $(1,4,3,2,2)$ model as our long-run equation to see the long-run relations of the variables when they are in their level form.

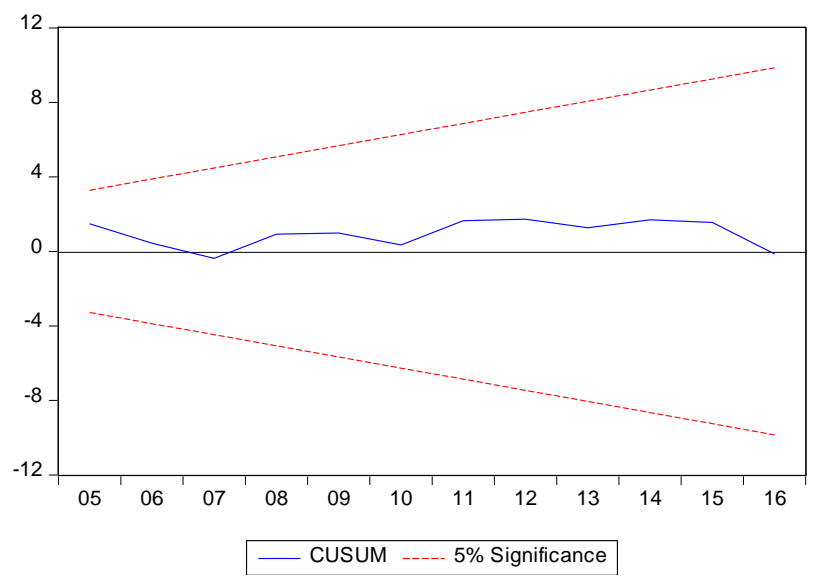

\section{Research Findings}

The long-run relationship in the level form of the ARDL for the unemployment equation is presented in the table below. We find that exchange rate and growth are also significant variables in our model together with the dummy controlling variable for the structural break 1980 -1999 pre-inflation targeting period and 20002017 inflation targeting period. We find a negative relationship between unemployment and inflation although it is weakly significant. This can be interpreted by stating that decreases in inflation may lead to increases in the unemployment rate. This does not agree with the basis of the monetary policy because it assumes that when inflation is low, that creates a conducive environment for investment that will create jobs. So low inflation should lead to low unemployment but this is not the case for South Africa since low inflation is facing increasing unemployment. There are certain inflation rates as eluded by Epstein (2002), that allows an economy to grow and according to his findings, any inflation rate until $20 \%$ is not detrimental to the macroeconomic environment of a certain economy. However, we find a contrary result to that. We find a positive relationship between the REER and unemployment. This may mean that when the rand depreciates, unemployment is increasing probably caused by continuous increases in prices of imported intermediate goods. Producers find it expensive to procure inputs hence there are high possibilities of expenditure switching where final products are imported for resale and that negatively affect employment. Economic growth is found to be significant although it is not an important variable in this case it is a variable that represents the behavior of the economy in terms of its capacity to create jobs.

Table 4: Estimated long-run coefficients of the ARDL $(1,4,3,2,2)$ unemployment equation

\begin{tabular}{lcccc}
\hline \multicolumn{1}{l}{ Dependent variable: Unemployment } & & & \\
\hline & Coefficient & Std. Error & T-Ratio & Prob \\
Inf & $*-0.3245$ & 0.1685 & -1.76 & $0.0780^{*}$ \\
Lreer & 16.7183 & 4.4612 & 3.7474 & $0.0022^{* * *}$ \\
Growth & -0.3800 & 0.1893 & -2.0069 & $0.0645^{*}$ \\
IT Dummy & 6.9369 & 2.1394 & 3.2424 & $0.0059^{* * *}$ \\
\hline Trend & 0.2303 & 0.1315 & 1.7508 & $0.1019^{*}$ \\
\hline
\end{tabular}

Source: Research results 
In this case real variables are affected by real factors like reducing inequality, improving technology, increasing public investment, reducing corruption and many others. Our study does not conform to the notion that in the short-run monetary policy affect real variables. South Africa has also adopted a freely floating exchange rate opening the economy to the world and letting the value of the rand be determined by the market. In our research we have found the exchange rate highly significant whilst having a positive effect on unemployment in the long-run.

Table 5: Error correction representation of the ARDL $(1,4,3,2,2)$ unemployment equation

\begin{tabular}{llccc}
\hline \multicolumn{1}{l}{ Dependent variable: dUemp } & & & \\
\hline & Coefficient & Std. Error & T-Ratio & Prob \\
dInf & -0.3245 & 0.1426 & -2.1368 & $0.0539^{* *}$ \\
dLReer & 16.7183 & 3.6988 & 4.5199 & $0.0005^{* * *}$ \\
dGrowth & -0.3800 & 0.1137 & -3.3416 & $0.0048^{* * *}$ \\
Trend & 0.2303 & 0.0399 & 5.7607 & $0.0000^{* * *}$ \\
Ecm & -0.9033 & 0.1091 & -8.2784 & $0.0000^{* * *}$ \\
\hline
\end{tabular}

R-square $=0.831526$

S.E of regression $=1.1872$

Adjusted R-squared $=0.700490$

Mean dependent var $=0.430303$

F-statistic $=6.345799$

Sum Squared resid $=25.37387$

$\mathrm{AIC}=3.484180$

S.D dependent var $=2.169459$

DW statistic $=2.482097$

Log likelihood $=-42.48898$

$\mathrm{SBC}=4.164411$

Source: Research results

Note: " $d$ " indicates the first difference, while " $L$ " denotes the logarithm of the variable

Table 5 above show the findings of the error correction model of the $(1,4,3,2,2)$ including all the model statistics that are relevant to be mentioned in this research. We find that changes in the current lags of inflation (inf) have negative effects on changes in unemployment (Unemp) and significant. The opposite goes to changes in positive current lags of the exchange rate (dLReer) that have positive and statistically significant effects on changes in unemployment (Unemp). This is a sign that when the rand depreciates it is causing harm to domestic industries basically through increases in prices of intermediary goods and they respond by cutting down employment in the short-run. We find that the speed of adjustment or our error correction coefficient (ECT) is highly significant and it holds the expected sign. The ECT is also within the range of (0 to -1) reducing doubts of us mis-specifying our model. The error correction term suggests a high speed of convergence to the long-run equilibrium because we see that almost $91 \%$ of the previous year's shock quickly adjusts back to the long-run equilibrium in the current year

\section{Discussion and Conclusion}

Our study confirms the long-run neutrality of money theory which states that changes in the quantity of money in a certain economy in the long-run are reflected only by changes in general price level not in "real" variables like unemployment and output. In our analysis we find that inflation does affect unemployment in the long-run and this suggests that South African Reserve Bank's policy remains doubtful in terms of its impact on unemployment. Since the inception of this monetary policy, unemployment has been increasing on a yearly basis whilst the rand has been losing value. The continuous depreciation of the rand is detrimental to local businesses that rely on importing their raw materials from foreign markets. The exchange rate passthrough strongly affect unemployment negatively. The rand depreciation was supposed to facilitate an increase in the volume of exports the country pushes into the global market as per a priori expectations but the quantity of exports South Africa is pushing continue to disappoint. It is only recently when world commodity prices have been sticky because of lack of demand on the world market that might somehow justify why export growth has been so weak to help curb unemployment in South Africa. Economic growth has the expected sign but very low in terms of its significance in explaining unemployment in the country. This implies that the economy has not been growing much for it to be able to highly impact unemployment. There is a need for a policy shift in South Africa if the economy is to start recovering to grow significantly for it to create sustainable jobs for the majority of unemployed people especially the youth. 
The detrimental effect of having a youth population which is unemployed is the risk of having an inexperienced future generation and it also exacerbates crime rate in the country and at the moment South Africa has the highest inmates in Africa and the majority of those are the youths. We could not find strong empirical evidence that explains the relationship between inflation and economic growth and then later affecting unemployment in South Africa. Basing on the findings of this paper we observe that a lot of things are not making theoretical sense economically. First, the rand has been depreciating but the country's exports have not been convincingly growing, inflation has been kept around 6\% but foreign direct investment (FDI) has not been increasing and we find a very weak relationship between FDI and unemployment. Also another interesting finding of our study is that FDI is not causing economic growth but economic growth cause FDI meaning to say that foreign investments follow an economy which is already doing well and not the reverse. This is not the case for South Africa because the economy has been growing by less than $3 \%$ for the past six to seven years hence it is justified why the economy has been failing to attract huge FDI inflows. Having observed that, we suggest that the Bank revise its monetary policy and widen its objectives and get involved in objectives that directly affect the social aspects of the economy. We are still acknowledging that it is the role of the fiscal policy in traditional economics but South Africa has become one of the most unequal economies in the world and the poverty and unemployment levels especially amongst the youth is a worrying factor demanding a huge policy shift. The Bank has enough manpower and capacity to research the best way it can target indicators like unemployment but at the same time not allowing inflation to go beyond a certain level. If the central bank can help to target and halve unemployment in the country, uncomfortable statistics of inequality and poverty in the country can be brought down to sustainable levels.

Another problem with the current monetary policy which can be one reason why it is failing to help to combat poverty and inequality is the fact that for it to sustain the inflation bandit has to use the interest rate. The South African interest rate is very high and unsustainable given the levels of poverty, inequality and unemployment in the country. This made us propose that maybe the inflation that the Bank is targeting is too low for the economy and the interest is too high. Comparing South Africa with its BRICS compatriots, South Africa is the only one with double-digit unemployment levels yet again the one with the highest interest rate. So the problem we see here is that South African policymakers want to benchmark the economy with economies that have better social problems than it has. We maintain that the right and appropriate money policy tailor-made for South Africa can be made and we propose targeting unemployment. This conclusion is in line with the findings of this study which has found a negative relationship between inflation and unemployment in South Africa as well as a positive relationship with the depreciation of the rand and unemployment. Finishing off, we would like to mention that our analysis might have some limitations. To start with we would like to acknowledge the fact that there are other variables that affect unemployment that were not included in this paper so our analysis is based on the variables we have included. Another factor is that different methodologies have been used by other scholars, the ones that capture structural shocks like the Vector Autoregressive (VAR) but our objective was to find the kind of relationship that exists between inflation and unemployment in the long-run. With that in mind, future studies can use other methodologies to continue exploring this interesting area.

\section{References}

Alexius, A. \& Holmlund, B. (2007). Monetary Policy and Swedish Unemployment Fluctuations. Economics Discussion Paper $\quad$ No. 2007-34. Available SSRN: https://ssrn.com/abstract=1716637 or http://dx.doi.org/10.2139/ssrn.1716637

Blinder, A. S. (2000). Central-bank credibility: Why do we care? how do we build it? American Economic Review, 90(5), 1421-1431.

Christiano, L. J., Eichenbaum, M. \& Evans, C. L. (1999). Monetary policy shocks: What have we learned and to what end? Handbook of Macroeconomics, 1, 65-148.

Daboussi, M. 0. (2014). Economic performance and inflation targeting in developing economies. Journal of World and Research, 3(1), 1-7.

Epstein, G. (2002). Employment-oriented central bank policy in an integrated world economy: A reform proposal for South Africa.

Epstein, G. \& Yeldan, E. (2006). Developing policy alternatives to inflation targeting, the new façade of neoliberal conditionality: an introduction, Amherst, MA: University of Massachusetts Amherst. 


\section{Journal of Economics and Behavioral Studies (ISSN: 2220-6140)}

Vol. 10, No. 4, pp. 88-96, August 2018

Epstein, G. (2007). Central banks, inflation targeting and employment creation, International Labor Office Group, W. B. (2017). World Development Indicators 2017, World Bank.

Kabundi, A. \& Schaling, E. (2013). Inflation and inflation expectations in South Africa: an attempt at explanation. South African Journal of Economics, 81(3), 346-355.

Leeper, E. M., Sims, C. A., Zha, T., Hall, R. E. \& Bernanke, B. S. (1996). What does monetary policy do? Brookings papers on economic activity, (2), 1-78.

Mboweni, T. (2003). African economic integration-keynote address at the 5th annual African development finance conference. South Africa. 9 October 2003.

Ngalawa, H. P. (2009). paper presented at the 14th Annual Conference of the African Econometric Society, 810 July 2009. Dynamic effects of monetary policy shocks in Malawi, Abuja, Nigeria.

Parsley, D. C. (2012). Exchange rate pass-through in South Africa: Panel evidence from individual goods and services. Journal of Development Studies, 48(7), 832-846.

Pesaran, M. H., Shin, Y. \& Smith, R. J. (1996). Testing for the Existence of a Long-run Relationship, Faculty of Economics, University of Cambridge.

Pesaran, M. H., Shin, Y. \& Smith, R. P. (1999). Pooled mean group estimation of dynamic heterogeneous panels. Journal of the American Statistical Association, 94(446), 621-634.

South African Reserve Bank (2016). Experience of Inflation targeting in S.A. SARB Quarterly Bulletin, (December 2016), 242-103.

South African Reserve Bank. (2004). Financial stability review. SARB Working Paper WP/02/04. Pretoria: South Africa.

Stats, SA. (2017). Quarterly labor force survey in South Africa, 2017 report, Pretoria, South Africa.

Walsh, C. E. (2009). Inflation targeting: what have we learned? International Finance, 12(2), 195-233.

World Bank. (2017). World development indicators, 2017 report, WDI56888, Volume 1. New York, USA. 